\title{
Prevalence of Emotional Distress in Cancer Patients
}

\author{
Manjeet Santre ${ }^{1}$, Jyoti Rathod ${ }^{2}$, S Maidapwad $^{3}$ \\ ${ }^{1}$ (Department of psychiatry, Dr.SC Government Medical College, Nanded, Maharashtra,India) \\ ${ }^{2}$ (Department of Psychology, INHS Asvini,Colaba,Mumbai,Maharashtra,India) \\ ${ }_{3}^{3}$ Department of Statistics, Dr.SC Government Medical College, Nanded, Maharashtra,India)
}

\begin{abstract}
:
Background: Emotional distress in cancer patients may interfere with the ability to cope effectively with cancer, its physical symptoms and its treatment. This in turn causes significant increase in psychiatric morbidity leading to poor outcome in the patients.

Objective: To assess prevalence of anxiety and depression and to study effects of socio demographic and cancer variables causing emotional distress.

Materials and Methods: The present cross-sectional hospital based study was conducted at Oncology department of tertiary care hospital after an approval from institutional ethical committee. The participants were included by random sampling method. Total 100 patients diagnosed by oncology physician or surgeon were interviewed after obtaining informed consent. The detailed information of study was given to every participant. Hospital Anxiety Depression Scale (HADS), a well validated, easy to administer and acceptable scale was used for measuring anxiety \& depression level. On HADS cut off score of >07 was taken as possible cases. Data collected was compiled, tabulated in Microsoft excel sheet and analyzed by SPSS software 16.0 versions with the help of a statistician.

Results: Thus 100 consecutive consenting diagnosed patients of cancer attending oncology department were studied. On Hospital Anxiety \& Depression Scale the mean anxiety and depression scores were 7.73 (SD - 4.57) \& 6.63 (SD - 4.23) respectively. The range of scores on anxiety subscale was $0-18$ \& $0-16$ on depression subscale. $47 \%$ had anxiety \& $39 \%$ were having depression with cut off score of $>07$ on each subscales. $23 \%$ of cancer patients were having scores in moderate to severe category on both HAD subscales. Total HADS score had range of 0-34 with mean of 14.21. 42\% cases were having emotional distress on HADS score (Total Score of $H A D S>15$ ).

Conclusion: On the basis of the study we would recommend that cancer patients require not only medical treatment approach but psychological measures as well to cope up with associated emotional distress. Early recognition and management of emotional distress will significantly decrease the burden on health care cost and improve the quality outcome in cancer treatment.
\end{abstract}

Key words: Anxiety, cancer, depression, emotional distress, psychological measures.

\section{Introduction}

Cancer is a life threatening disease. Its psychological impact on patients has been an important aspect for health professional involved in the treatment process. The diagnosis itself and subsequent treatment of cancer can be emotionally distressing. It is still considered synonymous with death, pain and suffering [1].

Apart from physical and financial draining it subsequently drains the patient emotionally. The actual symptom of the disease, its treatment as well as the patients and family member's perception and the social stigma attached to the disease causes significant emotional distress [2].

Emotional distress is a multi factorial unpleasant experience of emotional, cognitive, behavioral \& spiritual nature that interfere the ability to cope effectively with cancer. It extends in continuum ranging from common normal feeling of vulnerability, sadness and fear to problems that can become disabling anxiety, panic, social isolation and depression [3].

Across variety of studies clinically significant distress is reported in $25 \%$ of patients even though the range is from 5\%-50\% [4-9]. Although in large studies using standardized psychiatric interviews and applying diagnostic research criteria the range narrows from $10 \%$ to $30 \%$. In a large Meta analysis, the prevalence of anxiety has been found to be around $30 \%$ in cancer patients [10], while the depressive disorders affect up to $38 \%$ of the cancer patients [11-13]. Thus the considerable variation in prevalence rates is due to socio demographic variation of patient, disease related characteristics, patients pre morbid personality traits and different psychometric assessment tools used for assessment.

In spite of substantial proportion of patient of cancer suffer from emotional disturbance studies have consistently shown that primary care physician fail to identify anxiety and depression in their patients [14]. Consequence of this leads to decreased compliance to medical care, longer hospital stay, poorer quality of life, 
suicidal tendencies and increased morbidity. A timely psychiatric intervention can have better outcome in treatment and will be cost effective too [15-16].

With recent advancement in cancer treatment there is improved prognosis leading to longer survival rates. The longer survival has increased the emotional needs/demands of patients and inability to fulfill those leads to emotional distress and in turn increases the cost of treatment and eventually increases the morbidity and mortality.

Literature search showed that even though there are studies to detect emotional distress is done in western countries but there are very few studies in Indian setting. Chandra PS et al studied 294 newly admitted cancer patient at a hospital in south India and assessed the psychiatric morbidity in them [17]. We therefore aimed to measure the prevalence of anxiety $\&$ depression \& effects of socio demographic and clinical variables on emotional disturbance of cancer patient.

\section{Materials And Methods}

Participants in the present study were randomly selected. 47 male and 53 female, in the age range of 18-85 yrs, diagnosed with cancer at a tertiary care hospital were included in the study. Participants had a primary diagnosis of cancer in stage I-IV cancer and were undergoing different types of treatment. Eligible candidates were identified and after obtaining an informed consent questionnaire for psychometric test was given to patient. Those patients who were admitted in ICU on life support measures, unable to understand the questionnaire due to delirium were excluded from the study.

Patient demographic variables such as age, residence, occupation, marital status, education and type of family were recorded. Medical variables like participants disease stage (I-IV), treatment modality (like radio or chemo therapy) duration since diagnosis were obtained with the help from the on duty oncologist, staff of oncology department and the medical case papers of the patient.

Emotional distress was measured using HADS (Hospital Anxiety Depression Scale) psychological inventory. The HADS questionnaire consist of seven items on anxiety (HADS-A) and depression (HADS-D) subscale. The scale was chosen as it is well validated, acceptable to patients, easily understandable. To increase acceptability, symptoms of severe psychopathology have been omitted. HADS is used in patients with exclusion of symptoms caused by somatic illness [18]. HADS has been recommended for use in oncology patients [19]. The psychometric properties of HADS have been tested in HUNT study and they are considered to be excellent [20].

For anxiety disorder HADS (A) score of $\geq 7$ and HADS (D) score of $\geq 7$ for depression were taken as cut off score. HADS (A) focuses mainly on generalized anxiety issues of worry and fears of the future, with one item for panic attacks. HADS (D) focuses mainly on the reduced pleasure response aspect i.e., inability to derive pleasure from pleasurable activities. Walker et al [21] found that total HADS score with cut off 15 has an excellent sensitivity of 0.87 , specificity of 0.85 and Positive Predictive Value of 0.35 for Major depressive disorder. The reliability, validity and factor structure of the HADS has been established in a variety of clinical populations [22-25] of cancer patients. However HADS defined anxiety and depressive disorder are not identical to anxiety and depressive disorders as defined in DSM- IV edition [26].

Each item is scored from 0 (minimally present) to 3 (maximally present), and the sum score on each subscale HADS (A) and HADS (D) ranges from 0 to 21 and total maximum score of 42. During the interview all patients were interviewed by same set of examiners for maintaining the uniformity in the scoring and to avoid interview bias.

Data was compiled, tabulated in Microsoft excel sheet and analyzed with help of statistical software SPSS 16.0 version. The significance level was set at $\mathrm{P}<0.05$.

\section{Results}

In our study there were 53 females and 47 males. Mean age of cancer patients were 52 years. The age was in range from 18-81 years. Maximum patients were in the age group of 50-64. Mean years of schooling of the cases were 8.63 years. Maximum cases were educated between 6-11 standard. $37 \%$ of cancer patient were homemaker by occupation and $29 \%$ were dependent on their family members for their financial needs. On marital status $97 \%$ patients were married. $56 \%$ were from rural backgrounds that have come to this tertiary care centre for specialty treatment. 58\% patients had nuclear type of family. Maximum patients were in middle income category with only $06 \%$ in high income group.

$26 \%$ of patients were having genitourinary cancer which included cancer of prostate, bladder, uterus, cervix and ovaries. $22 \%$ were gastrointestinal cancer cases which included cancer of pancreas, small and large intestine, gall bladder \& peritoneum. Three quarter of the cases was diagnosed 6 months back \& $25 \%$ were diagnosed in less than 3 months period. $49 \%$ cases received chemotherapy and $8 \%$ cases are on radiation treatment. $49 \%$ patients were in stage I, $15 \%$ in stage III \& only $01 \%$ in stage IV of cancer staging. 
The correlation of HADS (A) \& (D) scores with respect to socio demographic and cancer variables are shown in Table $1 \& 2$ respectively.

On Hospital Anxiety \& Depression Scale the mean anxiety and depression scores were 7.73 (SD 4.57) \& 6.63 (SD 4.23) respectively. The range of scores on HADS (A) subscale was 0-18 \& 0-16 on HADS (D) subscale. Cut off score on both the subscale was $>07.47 \%$ had anxiety $\& 39 \%$ were having depression with cut off score of $>07.23 \%$ of cancer patients were having scores in range from 11-21 on both HAD subscales. Total HADS score had range of $0-34$ with mean of $14.21 .42 \%$ cases were having emotional distress on HADS score (Total score > 15).

TABLE No. 1

\begin{tabular}{|c|c|c|c|c|c|c|c|c|c|}
\hline \multicolumn{10}{|c|}{ Socio Demographic Variables with HADS Score of Cancer Patients } \\
\hline \multicolumn{2}{|c|}{ Variables } & \multicolumn{3}{|c|}{ HADS(A) Score } & \multirow{7}{*}{$\begin{array}{l}X^{2}=16.1 \\
1 \\
p-0.186\end{array}$} & \multicolumn{3}{|c|}{ HADS(D) Score } & \multirow{7}{*}{$\begin{array}{l}X^{2}-20.1 \\
p-0.054\end{array}$} \\
\hline & & $\begin{array}{c}\text { Mild } \\
(8-10)\end{array}$ & $\begin{array}{c}\text { Moderate } \\
(11-14)\end{array}$ & $\begin{array}{l}\text { Severe } \\
(15-21)\end{array}$ & & $\begin{array}{c}\text { Mild } \\
(8-10)\end{array}$ & $\begin{array}{c}\text { Moderate } \\
(11-14)\end{array}$ & $\begin{array}{l}\text { Severe } \\
(15-21)\end{array}$ & \\
\hline \multirow[t]{5}{*}{ Age (Yrs) } & $18-33$ & $2(33.3)$ & $00(0)$ & $1(16.7)$ & & $1(16.7)$ & $00(0)$ & $2(33.3)$ & \\
\hline & $34-49$ & $8(22.9)$ & $3(8.6)$ & $2(5.7)$ & & $3(8.6)$ & $5(14.3)$ & $1(2.9)$ & \\
\hline & $50-64$ & $10(22.2)$ & $9(20)$ & $3(6.7)$ & & $10(20.8)$ & $11(22.9)$ & $01(2.1)$ & \\
\hline & $65-79$ & $4(33.3)$ & $1(8.3)$ & $4(33.3)$ & & $02(18.2)$ & $02(18.2)$ & $01(9.1)$ & \\
\hline & $>80$ & $00(0)$ & $00(0)$ & $00(0)$ & & $00(0)$ & $00(0)$ & $00(0)$ & \\
\hline \multirow[t]{2}{*}{ Gender } & Female & $10(18.9)$ & $07(13.2)$ & $05(9.4)$ & \multirow{2}{*}{$\begin{array}{l}\mathrm{X}^{2}=1.919 \\
\mathrm{p}-0.589\end{array}$} & $09(17)$ & $07(13.2)$ & $04(7.5)$ & \multirow{2}{*}{$\begin{array}{l}\mathrm{X}^{2}=3.0 \\
\mathrm{p}-0.392\end{array}$} \\
\hline & Male & $14(29.8)$ & $06(12.8)$ & $05(10.6)$ & & $07(14.9)$ & $11(23.4)$ & $01(2.1)$ & \\
\hline \multirow[t]{2}{*}{ Marital } & Married & $22(22.7)$ & $13(13.4)$ & 09(9.3) & \multirow{2}{*}{$\begin{array}{l}X^{2}=6.071 \\
p-0.108\end{array}$} & $15(15.5)$ & $18(18.6)$ & $02(2.2)$ & \multirow{2}{*}{$\begin{array}{l}\mathrm{X}^{2}=26.54 \\
\mathrm{p}-0.00\end{array}$} \\
\hline & Unmarried & $00(0)$ & $02(66.7)$ & $00(0)$ & & 01(33.3) & $00(0)$ & 01(33.3) & \\
\hline \multirow{3}{*}{$\begin{array}{c}\text { Education } \\
\text { (yrs of } \\
\text { school) }\end{array}$} & $0-5$ & $3(15)$ & $3(15)$ & $4(20)$ & \multirow{3}{*}{$\begin{array}{l}\mathrm{X}^{2}=7.48 \\
\mathrm{p}-0.278\end{array}$} & $04(20)$ & $04(20)$ & $02(10)$ & \multirow{3}{*}{$\begin{array}{l}\mathrm{X}^{2}=2.25 \\
\mathrm{p}-0.894\end{array}$} \\
\hline & $6-11$ & $12(21.4)$ & $9(16.1)$ & $5(8.9)$ & & $09(16.1)$ & $10(17.6)$ & $02(3.6)$ & \\
\hline & $>12$ & $9(37.5)$ & $1(4.2)$ & $1(4.2)$ & & $03(12.5)$ & $04(16.7)$ & $01(4.2)$ & \\
\hline \multirow[t]{2}{*}{ Residence } & Rural & $06(10.7)$ & $08(14.3)$ & $07(12.5)$ & \multirow{2}{*}{$\begin{array}{l}\mathrm{X}^{2}=12.48 \\
\mathrm{p}-0.006\end{array}$} & $07(12.5)$ & $10(17.5)$ & $04(7.1)$ & \multirow{2}{*}{$\begin{array}{l}X^{2}=2.19 \\
p-0.534\end{array}$} \\
\hline & Urban & $18(40.9)$ & $05(11.4)$ & $03(6.8)$ & & $09(20.5)$ & $08(18.3)$ & $01(2.5)$ & \\
\hline \multirow[t]{2}{*}{ Family } & Joint & $08(19)$ & $10(23.8)$ & $14(9.5)$ & \multirow{2}{*}{$\begin{array}{l}X^{2}=7.66 \\
p-0.054\end{array}$} & $09(21.4)$ & $09(21.4)$ & $02(4.8)$ & \multirow{2}{*}{$\begin{array}{l}\mathrm{X}^{2}=2.69 \\
\mathrm{p}-0.441\end{array}$} \\
\hline & Nuclear & $16(27.6)$ & $03(5.2)$ & $06(10.4)$ & & $07(12.1)$ & $09(15.5)$ & $03(5.2)$ & \\
\hline \multirow[t]{5}{*}{$\begin{array}{l}\text { Income } \\
\text { (Rs.) }\end{array}$} & Up to 8000 & 02(11.8) & $00(0)$ & 03(17.6) & \multirow{5}{*}{$\begin{array}{l}\mathrm{X}^{2}=21.46 \\
\mathrm{p}-0.048\end{array}$} & 03(17.6) & 02(11.8) & 01(5.9) & \multirow{5}{*}{$\begin{array}{l}\mathrm{X}^{2}=15.42 \\
\mathrm{p}-0.217\end{array}$} \\
\hline & $8001-10000$ & $16(27.6)$ & $07(12.1)$ & $06(10.3)$ & & $09(15.5)$ & $12(20.7)$ & $03(5.2)$ & \\
\hline & $10001-12000$ & $03(7.6)$ & $05(29.4)$ & $00(0)$ & & 03(17.6) & $02(11.8)$ & $00(0)$ & \\
\hline & $12001-14000$ & $00(0)$ & $01(50)$ & $01(50)$ & & $01(50)$ & $00(0)$ & $01(50)$ & \\
\hline & $>14000$ & $03(50)$ & $00(0)$ & $0(0)$ & & $00(0)$ & $02(33.3)$ & $00(0)$ & \\
\hline \multirow[t]{4}{*}{ occupation } & Dependent & $5(17.2)$ & $4(13.8)$ & $06(20.7)$ & \multirow{4}{*}{$\begin{array}{l}\mathrm{X}^{2}=17.72 \\
\mathrm{p}-0.039\end{array}$} & $04(13.8)$ & $07(24.3)$ & $03(10.3)$ & \multirow{4}{*}{$\begin{array}{l}X^{2}=6.277 \\
p-0.712\end{array}$} \\
\hline & Employed & $07(58.3)$ & $00(0)$ & $00(0)$ & & $02(16.7)$ & $02(16.7)$ & $00(0)$ & \\
\hline & Homemaker & $06(16.2)$ & $04(10.8)$ & $03(8.1)$ & & $07(18.9)$ & $04(10.8)$ & $02(5.4)$ & \\
\hline & Retired & $06(27.3)$ & $05(22.7)$ & $01(4.5)$ & & $03(13.6)$ & $05(22.7)$ & $00(0)$ & \\
\hline
\end{tabular}

(Read the number in parentheses as percentages)

TABLE NO.2

Cancer Variables And HADS Score Of Cancer Patients

\begin{tabular}{|c|c|c|c|c|c|c|c|c|c|}
\hline & & \multicolumn{3}{|c|}{ HADS Score } & \multirow{2}{*}{$\mathbf{X}^{2}$} & \multicolumn{3}{|c|}{ HADS Score } & \multirow{2}{*}{$\mathbf{X}^{2}$} \\
\hline & & Mild & Moderate & Severe & & Mild & Moderate & Severe & \\
\hline \multirow{6}{*}{ Diagnosis } & Breast & $02(13.3)$ & $00(0)$ & 01(6.7) & \multirow{6}{*}{$\begin{array}{l}X^{2}=38.34 \\
p-0.012\end{array}$} & $01(6.7)$ & $02(13.3)$ & $00(0)$ & \multirow{6}{*}{$\begin{array}{l}X^{2}=47.83 \\
p-0.001\end{array}$} \\
\hline & $\begin{array}{c}\text { Head, neck \& } \\
\text { face }\end{array}$ & $00(0)$ & 03(33.3) & $00(0)$ & & $00(0)$ & 03(33.3) & $00(0)$ & \\
\hline & Gastrointestinal & $08(36.4)$ & $02(9.1)$ & $04(18.2)$ & & $05(22.7)$ & $05(22.1)$ & $01(4.5)$ & \\
\hline & Genitourinary & $04(15.4)$ & $05(19.2)$ & $01(3.8)$ & & $07(26.9)$ & $02(7.7)$ & $01(3.8)$ & \\
\hline & Lung carcinoma & $03(30)$ & $01(10)$ & $02(20)$ & & $01(10)$ & $02(20)$ & $00(0)$ & \\
\hline & Sarcoma & $01(20)$ & $02(40)$ & $02(40)$ & & $00(0)$ & $02(40)$ & $03(60)$ & \\
\hline \multirow{2}{*}{ Duration } & $<06$ Month & $06(24)$ & $01(4)$ & $02(8)$ & \multirow{2}{*}{$\begin{array}{l}\mathrm{X}^{2}=2.97 \\
\mathrm{p}-0.396\end{array}$} & $04(16)$ & $03(12)$ & $02(8)$ & \multirow{2}{*}{$\begin{array}{c}\mathrm{X}^{2}=1.316 \\
\mathrm{p}-0.725 \\
\end{array}$} \\
\hline & $>06$ Month & $18(24)$ & $12(16)$ & $08(10.7)$ & & $12(16)$ & $15(20)$ & $03(4)$ & \\
\hline Staging & I & $10(20.4)$ & $04(8.2)$ & $00(0)$ & $\mathrm{X}^{2}=32.61$ & $09(18.4)$ & $04(8.2)$ & $00(0)$ & $\mathrm{X}^{2}=17.92$ \\
\hline
\end{tabular}


Prevalence of Emotional Distress in Cancer Patients

\begin{tabular}{|c|c|c|c|c|c|c|c|c|c|}
\hline & II & $08(22.9)$ & $07(20)$ & 04(11.4) & \multirow[t]{2}{*}{$p-0.000$} & $05(14.3)$ & $08(22.9)$ & $03(8.6)$ & \multirow[t]{2}{*}{$\mathrm{p}-0.036$} \\
\hline & IV & $01(100)$ & $00(0)$ & $00(0)$ & & $00(0)$ & $01(100)$ & $00(0)$ & \\
\hline \multirow{3}{*}{ Treatment } & Operated & $06(21.4)$ & $02(7.1)$ & $00(0)$ & \multirow{3}{*}{$\begin{array}{c}\mathrm{X}^{2}=33.37 \\
\mathrm{p}-0.000\end{array}$} & $03(10.7)$ & $03(10.7)$ & $00(0)$ & \multirow{3}{*}{$\begin{array}{c}X^{2}=21.31 \\
p-0.011\end{array}$} \\
\hline & Palliative & $05(33.3)$ & $02(13.3)$ & $05(33.3)$ & & $04(26.7)$ & $05(33.3)$ & $00(0)$ & \\
\hline & Radiotherapy & $02(25)$ & $04(50)$ & $02(25)$ & & $02(25)$ & $03(37.5)$ & $02(25)$ & \\
\hline
\end{tabular}

(Read the number in parentheses as percentages)

\section{Discussion}

Emotional distress of some degree is always associated with a diagnosis of cancer. With advancement in treatment modalities and longer survival rates there has been increase in the emotional needs of the patients. Early recognition of the emotional requirements by the oncologist or the health professional involved in the treatment process not only decrease the cost burden of cancer treatment but at the same time improve quality of life.

The study was conducted to assess the level of anxiety and depression in cancer patients. In search of causative factors in relation to production of anxiety and depression various socio demographic and cancer variables were considered.

The socio demographic results showed that there was increased proportion of depression as age advances in cancer patient $(\mathrm{P}<0.054)$. Even though prior studies found to have psychological distress on lower side in older patients [27] but some studies do not found any association between age and psychological well being or distress [28-29]. However, in our study the older age was found to have increased distress on HADS (D) subscale may be due to impact of more extensive surgery or the side effects of chemotherapy or radiotherapy. These procedures produce limitations in activity causing distress or may be due to poor coping skills of the patient.

In our study result there were no statistically significant differences in gender of cancer patients with the distress even though the study done by Goldzweiz $G$ et al [30] revealed that men were found to be more distressed than their wives $(\mathrm{p}<0.0001)$. Even though men reported receiving more support from their wives than did the female spouses $(\mathrm{p}<0.0005)$ still men report higher level of psychological distress as they do not use the support as effectively as their wives. These differences can be related to cultural characteristics of that particular society.

In our study there was statistically significant score on marital status variable on HADS (D) sub scale which was consistent to the study done by Goldzweig G, et al [31]. In our study result in residential background of the patient there were statistically significant scores on residence $(\mathrm{P}<0.006)$, family type $(\mathrm{p}<0.054) \&$ occupation $(\mathrm{P}<0.039)$ of the cases. These findings were consistent with the findings of prior studies done by Parle et al [32] \& Bowman et al [33].

Educational status the scores on anxiety and depression were proportionately higher on lower education, this findings corroborates with the findings of Parker et al [34] who found that greater educational level and greater social support reported better quality of life in terms of psychological well being .

Our study we found statistically significant anxiety scores in patients having low income. This is in concurrence with prior study done by Nordin et al [35] and A Alacacioglu et al [36]. Thus this study shows that the economy plays an important role in the life of patients to fight against cancer.

On occupational status of the patient the $\mathrm{P}$ value was 0.039 and 0.712 on anxiety and depression scale respectively. This might be because the perceived burden of the continuation of the work and the frequent hospital visit leading to poor work performance, frequent absenteeism and fear of removal from the employment place all leads to increased emotional distress in patients.

Zabora et al [37] studied 4496 cancer patients with 14 different diagnoses. He found overall prevalence of distress to be $35.1 \%$ with anxiety and depression $24.1 \%$ \& $18.7 \%$ respectively. For measurement he used BSI (Brief Symptom Inventory) scale with global severity index for total symptom score $>63$ on either BSI scale. He found that distress rate varied from $43.4 \%$ for lung carcinoma to 29.6 for gynecological cancers while pancreatic cancer produced highest mean scores on anxiety and depression while Hodgkin's lymphoma exhibited highest mean score on hostility criteria. Thus the cancer site affects quality of life and psychological well being differently similarly our findings are in concurrence to previous studies which shows that variable site of cancer produces different types of emotional responses in patients.

In cancer staging the anxiety and depression scores were statistically significant on Pearson chi square test. For HADS (A) \& HADS (D) the values were $\mathrm{P}<0.000 \& \mathrm{P}<0.036$ respectively. These results were in agreement with the study done by Noyes et al [38]. In their study 400 cancer patients were given Illness distress scale (IDS) in which they found that younger patient with advanced disease scored higher on the scale. Score on this scale correlated highly with measure of depression by the Becks Depression Inventory (BDI). Similarly Couper JW et al [39] in their study found that advanced cancer causes more psychological distress compared to 
early prostate cancer. Norton et al [40] too found that with more advanced or recurrent disease ovarian cancer patient experienced greater psychological distress. In their study the distress was measured using BDI (Becks Depression Inventory, The Mental Health Inventory \& Impact Event Scale).

During the treatment phase of the individuals they have significant levels of emotional distress. This distress is pertaining to different modalities of treatment option available to the patient offered by the health provider. The type of treatment whether operative or non operative, schedule of treatment, side effect of treatment, anxiety regarding the intervention procedures, cost of treatment, self analysis of the treatment modalities from the knowledge which patient gathers from various sources and finally the thought regarding outcome of the treatment all this leads to distress. In our study also patients have statistically significant scores on anxiety and depression subscales which are in agreement with prior studies which found that during the treatment phase the emotional distress significantly changes [41-43].

Some limitations of the study need to be mentioned. The sample size studied was small in number. Since situational anxiety and distress precedes every intervention hence assessment prior to this might not appropriately predict emotional distress. Personality traits of the subject can also influence the emotional reaction to the stressors which we did not assess. The measurement tool used also has bias as our results were based on the score of questionnaire and not on clinical interview and hence many patients having transient distress were also included in the distress group which might influence our study result.

\section{Conclusion}

Our findings indicate that emotional distress to cancer is prevalent among cancer patient suggesting that they should be carefully assessed to determine whether these symptoms warranted attention. Psychiatric professional can minimize this emotional distress by timely addressing the problem and providing them with appropriate treatment.

Awareness to identify the risk factors causing emotional distress needs to be created in oncologist for early detection of serious emotional reactions. This will help in early diagnosis and treatment of psychiatric morbidity and in turn will improve quality of life of cancer survivors \& reduce the economic burden of such patients in developing countries like India.

\section{References}

[1] Powe BD, Finne R. Cancer fatalism: the state of the science. Cancer Nurs 2003, 26, 454-465.

[2] Lesko LM. Psychological issues. In : Devita VT, Hellman S,Rosenberg SA, editors, 5th ed. (1997) Cancer Principles and Practice of Oncology, New York : Lippincott Raven; 2879-90.

[3] Carlson L, Bultz B Cancer distress screening: needs, models and methods. J Psychosom Res 2003, 55,403-409

[4] Aass N, Fossa SD, Dahl AA, Moe TJ: Prevalence of anxiety and depression in cancer patients seen at the Norwegian Radium Hospital. Eur J Cancer, 1997, 33, 1597-1604.

[5] Costantin M, Musso M, Viterboli P: Detecting psychological distress in cancer patients: validity of the Italian version of the Hospital Anxiety and Depression Scale. Support Care Cancer 1999, 7,121-127.

[6] Montazeri A, Milroy R, Hole D, McEwean J, Gills CR: Anxiety and depression in patients with lung cancer before and after diagnosis: findings from a population in Glasgow, Scatland. J Epidemiol Community Health 1998, 52, $203-204$.

[7] Hopwood P, Howell A, Maguire P. Psychiatric morbidity in patients with advanced cancer of the breast: prevalence measured by two self-rating questionnaires. Br J Cancer 1991, 64, 349-352.

[8] Ford S, Lewis S, Fallowfield L. Psychological morbidity in newly referred patients with cancer. J Psychosom Res 1995, 39, 193202.

[9] Ibbotson T, Maguire P, Selby P et al. Screening for anxiety and depression in cancer patients: the effects of disease and treatment. Eur J Cancer 1994, 30A, 37-40.

[10] Stark DP, House A: Anxiety in cancer patients. Br J Cancer 2000, 83:1261-1267.

[11] Honda K, Goodwin RD: Cancer and mental disorders in a national community sample: Findings from the national comorbidity survey. Psychother Psychosom 2004, 73, 235-242

[12] Massie MJ: Prevalence of depression in patients with cancer. J Natl Cancer Inst Monogr.2004, 32, 57-71

[13] Pirl WF: Evidence report on the occurrence, assessment, and treatment of depression in cancer patients. J Natl Cancer Inst Monogr 2004, 32, 32-39

[14] Passik SD, Dugan W, et al: Oncologists' recognition of depression in their patients with cancer. J Clin Oncol 1998, 16, 1594-1600

[15] Ashraf S, Gupta AK, et al. Effect of short term psychiatric intervention in cancer patients. Med J Armed Forces India, 2004, 60,109-12.

[16] Payne DK, Hoffman RG, Theodoulou M, Dosik M,Massie MJ. Screening for anxiety and depression in women with breast cancer .Psychiatry and medical oncology group managed care. Psychosomatics 1999, 40, 64-9.

[17] Chandra PS, Chaturvedi SK, Kumar A, Kumar S, Subbakrishna DK, Channabasavanna SM et al Awareness of diagnosis and psychiatric morbidity among cancer patients: a study from south India. J Psychosom Res 1998, 45, $257-61$.

[18] Zigmond AS, Snaith RP: The Hospital Anxiety and Depression scale. Acta Psychiatr Scand 1983, 67, 361-370.

[19] Sharpe M, Strong V, Allen K, et al: Major depression in outpatients attending a regional cancer centre: Screening and unmet treatment needs. Br J Cancer 2004, 90, 314-320

[20] Mykletun A, Stordal E, Dahl AA: The Hospital Anxiety and Depression Scale (HADS): Factor structure, item analyses, and internal consistency in a large population. Br J Psychiatry 2001, 179, 540-544

[21] Walker J, Postma K, McHugh GS, et al: Performance of the Hospital Anxiety and Depression Scale (HADS) as a screening tool for major depressive disorder in cancer patients. J Psychosom Res 2007, 63, 83-91

[22] Moorey S, Greer S, Watson M, Gorman C, Rowden L, Tunmore R, Robertson B, Bliss J The factor structure and factor stability of the hospital anxiety and depression scale in patients with cancer. Br J Psychiatry 1991, 158, 255-259 
[23] Johnston M, Pollard B, Hennessey P Construct validation of the hospital anxiety and depression scale with clinical populations. J Psychosom Res 2000, 48, 579-584

[24] Mykletun A, Stordal E, Dahl A Hospital Anxiety and Depression (HAD) scale: factor structure, item analyses and internal consistency in a large population. Br J Psychiat 2001,179, 540-544

[25] Smith A, Selby P, Velikova G, Stark D, Wright E, Gould A, Cull A Factor analysis of the Hospital Anxiety and Depression Scale from a large cancer population. Psychol Psychother: theory, Res Practice 2002, 75,165-176

[26] Stordal E, Bjartveit Kru“ger M, Dahl NH, et al: Depression in relation to age and gender in the general population: The NordTrøndelag Health Study (HUNT). Acta Psychiatr Scand 2001, 104, 210-216

[27] Mor V, Allen S, Malin M. The psychosocial impact of cancer on older versus younger patients and their families. Cancer 1994, 74, 2118-27

[28] Stefanek ME,Derogatis LP,Shaw A. Psychosocial distress among oncology out patients. Prevalence and severity as measured by Brief Symptom Inventory.Psychosomatics 1987, 28, 530-9.

[29] Greime ER, Padilla GV, Grant MM. Physical and psychosocial outcomes in cancer patients: a comparison of different age groups. Br J Cancer 1997,76, 251-5.

[30] Goldzweig G, Hubert A, Walach N, Brenner B, Perry S, Andritsch E, Baider L. Gender and psychological distress among middleand older-aged colorectal cancer patients and their spouses: an unexpected outcome. Crit Rev Oncol Hematol. 2009, 70(1), 71-82

[31] Goldzweig G, andritsch E, Hubert A, Walach N, Perry S, Brenner B,Baider L, Psycho oncology 2009, Aug ,18 (8), 866-74

[32] Parle M, Gallagher J, Gray C, Akers G, Liebert B. From evidence to practice: factors affecting the specialist breast nurse's detection of psychological morbidity in women with breast cancer. Psycho-Oncology 2001,10,503-10.

[33] Bowman KF, Deimling GT, Smerglia V, Sage P, Kahana B. Appraisal of the cancer experience by older long-term survivors. Psycho-Oncology 2003, 12, 226-38.

[34] Parker PA, Baile, WF, de Moor C, Cohen L Psychosocial and demographic predictors of quality of life in a large sample of cancer patients. Psycho-Oncology 2003,12,183-93.

[35] Nordin K, Berglung G, Glimelius B et al. Predicting anxiety and depression among cancer patients: a clinical model. Eur J Cancer 2001, 37, 376-384.

[36] A. Alacacioglu, O. Tarhan, I. Alacacioglu, A. Dirican, U. Yilmaz : Depression and anxiety in cancer patients and their relatives; JBUON 201, 18(3), 767-774,

[37] Zabora J, Brintzenhofeszoc K, Curbow B, Hooker C, Piantadosi S. The prevalence of psychological distress by cancer site. Psycho oncology 2001, 10, 19-28

[38] Noyes. Distress associated with cancer as measured by the Illness Distress Scale. Psychosomatics, 1990, 31, 321-30.

[39] Couper JW,Love AW,DuchesreGM, BhochS, Marvean M, Dunai JW,Scealy M,Costello A, Krissane DW, predictors of psychological distress 12 months after diagnosis with early and advanced prostate cancer. Med J Aust 2010, 193(5 suppl), 58-61

[40] Tina R Norton, Sharon L, Mitchell I,Edel son,Norman Rosenblum,David Warshal \& Synthia Bergman, Prevalence and predictors of psychological distress among women with ovarian cancer. J Clin Oncol, 2004, 22,919-926.

[41] Hahn CA, Dunne R, Halperin EC. Routine screening for depression in radiation oncology patients. Am J Clin Oncol 2004, 27,497-9

[42] Middleboe T. Depressive symptoms in cancer patients undergoing chemotherapy: A psychometric analysis. Psychotherapy psychosomatics, 1994, 61,171-7.

[43] Silberfarb PM, Philibert D, Levine PM. Psychosocial aspects of neoplastic disease:II. Affective and cognitive effects of chemotherapy in cancer patients. Am J of Psychiatry, 1980, 137, 597-601. 